\title{
Naturally Occurring Phenols Modulate Vegetative Growth and Deoxynivalenol Biosynthesis in Fusarium graminearum
}

Safa Oufensou ${ }^{+*}$, Virgilio Balmas ${ }^{+}$, Emanuela Azara ${ }^{\ddagger}$, Davide Fabbri ${ }^{\ddagger}$, M. Antonietta Dettori ${ }^{\ddagger}$, Christoph Schüller ${ }^{\S}$, Franz Zehetbauer', Joseph Strauss ${ }^{\S, l}$, Giovanna Delogu ${ }^{\ddagger}$, Quirico Migheli ${ }^{+, \#}$

${ }^{+}$Dipartimento di Agraria, Università degli Studi di Sassari, Via E. De Nicola 9, 07100 Sassari, Italy. ${ }^{\ddagger}$ Istituto CNR di Chimica Biomolecolare, Traversa La Crucca 3, I-07100 Sassari, Italy. ${ }^{\S}$ Bioactive Microbial Metabolites (BiMM) Research Platform, University of Natural Resources and Life Sciences Vienna, (BOKU), 3430 Tulln, Austria. "Institute of Microbial Genetics, Department of Applied Genetics and Cell Biology (DAGZ), University of Natural Resources and Life Sciences Vienna, (BOKU), 3430 Tulln, Austria. "Nucleo di Ricerca sulla Desertificazione, Università degli Studi di Sassari, Via E. De Nicola 9, 07100 Sassari, Italy. 
Table S1. Measurement of $\mathrm{pH}$ in liquid FMM amended with L-ornithine $(5 \mathrm{mM})$ and different phenolic compounds after 14, 36, 72 and 96 hours post inoculation (h) with Fusarium graminearum wild type $\mathrm{PH}-1$ at $24{ }^{\circ} \mathrm{C}$.

Table S2. Summary table of the tested compounds responses relative to the control (untreated) in terms of inhibition of mycelial growth, Tri5::gpf expression, modulation of mycotoxin production and buffering ability. Percentages are calculated at $32 \mathrm{~h}$ when the untreated fluorescence curve reached the maximum value and, in term of OD, the fungi is in the exponential growth phase.

${ }^{\text {a }}$ Percentage (\%) of vegetative growth compared to the untreated control; ${ }^{\mathbf{b}} \%$ of Tri5::gfp expression compared to the untreated contro; ${ }^{\mathbf{c}}$ Tri5::gfp expression normalised to the fungal growth (OD); ${ }^{\mathbf{d}}$ Tri5::gfp transcription, DR: Down regulated; ${ }^{\mathbf{e}}$ Effect of the compound on $\mathrm{pH}$ medium up to $96 \mathrm{~h} ;{ }^{\mathbf{f}}$ Concentration of DON produced $(\mu \mathrm{g} / \mathrm{mL}) ;{ }^{\mathbf{g}}$ Concentration of 3-ADON produced $(\mu \mathrm{g} / \mathrm{mL}) ;{ }^{\mathbf{h}}$ Concentration of 15 -ADON produced $(\mu \mathrm{g} / \mathrm{mL})$; $*$ Statistically different from the untreated control, $p<0.05$; **: statistically different from the untreated, $p<0.01$;

--: no vegetative growth; NF: Not Found. 
Table S1

\begin{tabular}{|c|c|c|c|c|c|c|}
\hline \multirow[t]{2}{*}{ Treatment } & \multirow{2}{*}{$\begin{array}{l}\text { Molarity } \\
(\mathrm{mM})\end{array}$} & \multicolumn{5}{|c|}{$\mathrm{pH}$ value } \\
\hline & & 0 & $14 \mathrm{~h}$ & $36 \mathrm{~h}$ & $72 \mathrm{~h}$ & $96 \mathrm{~h}$ \\
\hline Control & -- & 7.51 & 7.41 & 7.11 & 4.6 & 4.53 \\
\hline Ferulic acid & 0.5 & 7.23 & 7.15 & 6.72 & 4.26 & 3.85 \\
\hline Apocynin & 0.5 & 7.50 & 7.42 & 7.12 & 5.18 & 4.90 \\
\hline Honokiol & 0.5 & 7.59 & 7.56 & 7.52 & 7.41 & 7.27 \\
\hline Magnolol & 0.5 & 7.50 & 7.49 & 7.65 & 7.49 & 7.64 \\
\hline Magnolol & 0.25 & 7.56 & 7.53 & 7.45 & 7.73 & 7.74 \\
\hline Thymol & 0.5 & 7.50 & 7.58 & 7.58 & 7.23 & 5.50 \\
\hline Thymol & 0.25 & 7.54 & 7.50 & 7.23 & 4.55 & 4.43 \\
\hline Magnolol+Thymol & $0.25+0.25$ & 7.55 & 7.48 & 7.64 & 7.78 & 7.38 \\
\hline
\end{tabular}


Table S2

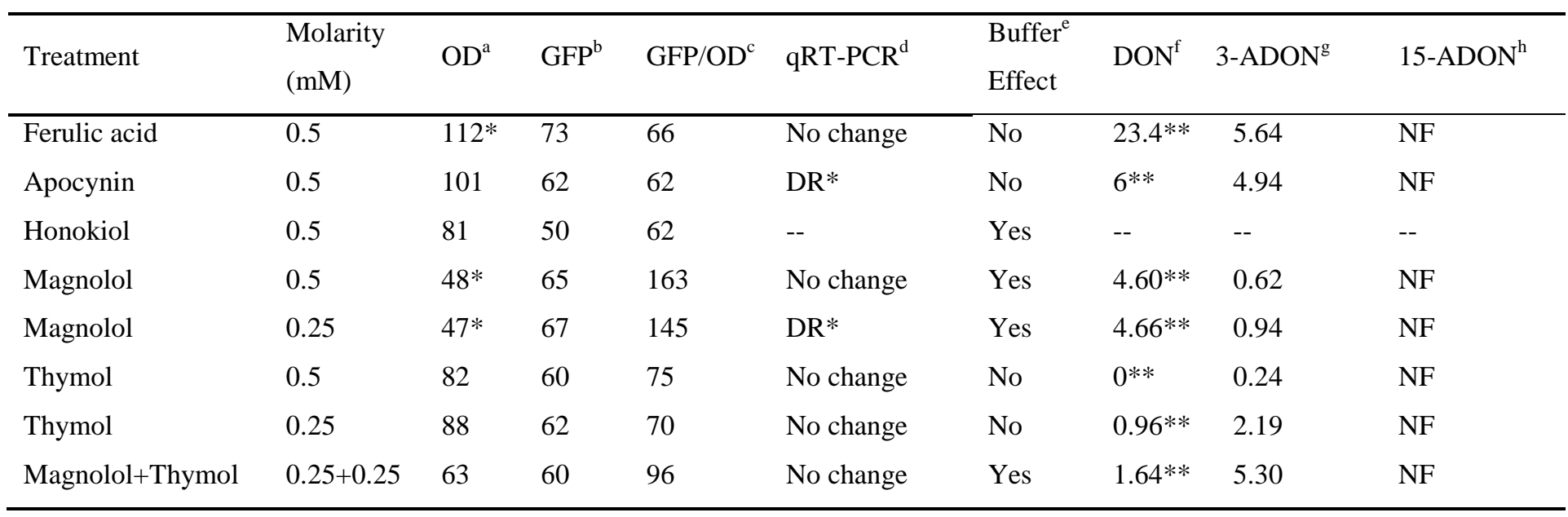

